\title{
Implementation of Modified Differential Evolution Algorithm for Hybrid Renewable Energy System
}

\author{
G. R. Venkatakrishnan ${ }^{\mathrm{a}, *}$, R. Rengaraj ${ }^{\mathrm{a}}$, K. K. Sathish ${ }^{\mathrm{b}}$, R. K. Dinesh ${ }^{\mathrm{a}}$, T. Nishanth ${ }^{\mathrm{a}}$ \\ ${ }^{a}$ Department of Electrical and Electronics Engineering, Sri Sivasubramaniya Nadar College of Engineering, Kalavakkam, Chennai \\ ${ }^{b}$ Department of Chemical Engineering, Sri Sivasubramaniya Nadar College of Engineering, Kalavakkam, Chennai
}

\begin{abstract}
A hybrid renewable energy system, which could provide a reliable energy alternative for conventional Battery systems is implemented in this paper. The primary requirement is that the hybrid energy system should be cost-effective while meeting the energy demand. The hybrid system is implemented to a area located in Uttarakhand, India using solar photovoltaic cells to supply power during hot and humid conditions and using wind turbine generators to supply power during windy conditions. The wind turbine generators and photovoltaic cells are used in a combined manner along with the diesel generators as in case if it fails to meet the demand. In order to meet the requirements, modified Differential Evolution (DE) Algorithm is being implemented. Moreover, the effectiveness of the performance is evaluated by comparing the results obtained from modified DE with other optimization algorithms. In comparison with other optimization algorithms, results indicate that the implementation of the modified DE algorithm helps in obtaining the best cost effective solution for the system along with meeting the energy demand.
\end{abstract}

DOI: $10.46481 /$ jnsps.2021.240

Keywords: Hybrid systems, Evolutionary algorithms, Renewable energy, Differential evolution

Article History :

Received: 28 May 2021

Received in revised form: 22 June 2021

Accepted for publication: 18 July 2021

Published: 29 August 2021

(c)2021 Journal of the Nigerian Society of Physical Sciences. All rights reserved. Communicated by: E. Etim

\section{Introduction}

Complexity and size of the power system is increasing day by day, owing to increasing population and demand of electricity. Hence, a continuous and reliable supply of electricity is the most important requirement of industries and other fields. In the modern integrated power system, due to unaccommodating requirements various challenging problems are imposed on the electrical utilities. Thus, a proper planning of the power system using the optimal operation technique is required at a

\footnotetext{
${ }^{*}$ Corresponding author tel. no:

Email address: venkatakrishnangr@ssn.edu . in (G. R. Venkatakrishnan )
}

high level. The power system when it is optimally operated determines the best system state by considering all kinds of constraints to which it is subjected. The different considerations by which the power system can be operated optimally are either the economics of operation or system security or emission of fossil fuel plant. Since this consideration makes a conflict over one another, a compromise between these is required to operate the power system optimally. Among the different consideration, the ideology of using the available power efficiently among the public and government, the economic analysis of power system has gained more importance when compared to others.

Hence the importance and the implementation of renewable energy resources come into existence. In order to save fossil fuels and to reduce the harmful greenhouse gasses emissions, re- 
newable energy resources must be exploited at a greater extent. Hence, the sustainability of such a system will be questioned as these renewable resources are not found throughout the year around. Therefore, it is better to implement a hybrid system in such a case where if one part of the system falls back, there are other resources to help meet the demand. Now, we would have to have a proper optimization of the given resources to attain a maximum efficiency and at a minimum cost. Although there a lot of iterative approaches in existence, the best way to optimize them would be the implementation of the evolutionary algorithms. The reasons for the implementations of the evolutionary algorithms than its counterparts as well as the advantages of the Modified DE algorithm over other algorithms are discussed as follows.

Abbaas Azarpour et al have discussed the importance of renewable energy resources in their paper [1]. More emphasis is given over the ill-effects caused by these renewable energy resources in addition to their advantages over conventional sources of energy such as fossil fuels, etc. The effects caused by each renewable energy source are explained in this paper. The increasing usage of fossil fuels has lead to its depletion and thus the advantages of the usage of solar energy to countries that lie in the equator have been studied by Ho Soonmin[2,3]. The importance of wind energy was being highlighted by Tarang Agarwal et al[4]. The various issues and challenges faced by a country while installing a standalone wind turbine system was being put forward in this paper. The various issues includes grid related issues, design issues, location issues, and its impact on the environment.

Now, when all these renewable energy sources are considered individually, they have their drawbacks. For instance, the solar plants have certain disadvantages, such as high installation costs, and the peak output would not be obtained during the cloudy and windy days. The biomass plant's maximum output reduces during the lower temperature - similarly, the wind turbines become faulty during very high or during very lowspeed applications. So, to relinquish the drawbacks of one of the sources, renewable resources are used in a combined manner. Renewable resources when combined, for instance, if wind and solar plant combine, then during cloudy days, the wind turbine's output increases. During the hot and humid climates, solar plants produce a peak output. Thus, the drawback of one of the resources is compensated in the other while using hybrid renewable energy resources.

Various types including Hybrid Wind-Solar energy system, Hybrid Wind-Solar diesel energy system, Hybrid Wind-Diesel energy system, Hybrid Solar-Diesel energy system and various other hybrid systems are being discussed in [5]. A small brief summary about the various types are being discussed. Then, small introductions about the various types of optimization algorithms that can be included in these systems are being summarized. The paper concludes by saying that with hybrid renewable energy systems, it is possible to achieve better results, at lower cost and hence save resources.

The combination of wind as well as solar energy systems with battery as a backup source was being implemented to various test case systems in [6] and [7]. Particle swarm optimiza- tion (PSO) method was being implemented to achieve the power demand individually for every particular house from a hybrid renewable energy system was being implemented [8]. A Hybrid renewable energy system (HRES) combining PV, Wind as well as Biomass energy systems was being implemented [9]. Based on minimal cost of energy, the optimal configuration for the HRES system is obtained. The optimal solution is being obtained using genetic algorithm (GA) and PSO and the end results were being tabulated.

A new approach was being implemented to reduce the dependence on diesel generators by an optimal combination of the solar, and wind system with the backup of a battery storage system being implemented [10]. A comprehensive review consisting sizing and optimization of hybrid PV-wind energy system was being studied and discussed thoroughly by Hadi Nabipour-Afrouzi et al [11].

Conventional methods became less used owing to the fact that these methods face a lot of disadvantages when compared to the modern optimization algorithms. Conventional methods were satisfactorily successful for purely continuous variable optimal power flow, whereas that is not the situation in for real life problems as there exists several discrete control variables. Over the past few decades, many new evolutionary algorithms have been developed to overcome the conventional methods. Different evolution (DE) algorithm is one of the evolutionary algorithms which has been implemented in solving problems in different engineering fields.

The DE algorithm has been implemented to a standard IEEE 30 system with 6 thermal plants and 2 wind farms [12]. In [13-21], DE algorithm is used to optimize the parameters in different power system problems. But the success of DE algorithm depends on the choice of parameters like population size $n p$, mutation rate $F$ and crossover rate $C R$ varies its performance (searching accuracy and convergence speed). Hence, in [22], an improved version of DE algorithm is implemented to solve the above complex non-linear problems. In this paper, that modified DE algorithm is being used to optimize the various parameters of the HRES system in [23], and the objective function is to minimize the final system cost. It helps identify the best possible combination of the hybrid system components which meets the demand as well as possessing the minimum cost. The end results are a final tabulation comparing the results obtained from GA, PSO and Modified DE. Figure 1 depicts the block diagram of chosen system.

\section{Modelling of Hybrid System}

\subsection{PV System}

The hourly power output of the PV array is calculated using Eqn. (1) as follows:

$$
P_{p v}^{t}=f_{p v} * Y_{p v} *\left(\frac{I_{T}}{I_{S}}\right)
$$

where, $P_{p v}^{t}$ is the hourly power output of the PV array in $\mathrm{kW}$, $f_{p v}$ is the PV Derating Factor, $Y_{p v}$ is the PV array capacity in $\mathrm{kW}, I_{T}$ is the global solar radiation incident on the PV Array and $I_{S}$ is equal to $1 \mathrm{~kW} / \mathrm{m}^{2}$ 


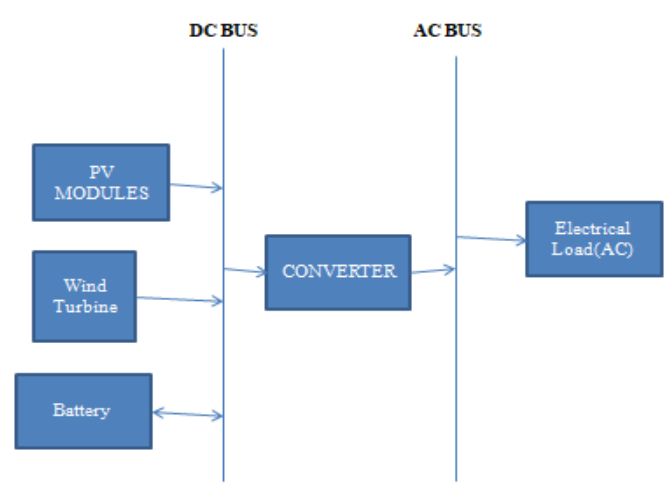

Figure 1. Block diagram of Hybrid system

\subsection{Wind Turbine Generator}

The wind turbine generator's power output is calculated using Eqn. (2) as

$$
\frac{V\left(h \_h u b\right)}{V\left(h \_ \text {anem }\right)}=\left(\frac{h \_ \text {hub }}{h \_ \text {anem }}\right)^{\alpha}
$$

where, $h \_$anemis the anemometer height in meter $(\mathrm{m}), h \_h u b$ is the hub height in meters $(\mathrm{m}), V\left(h_{-}\right.$anem $)$is the speed of the wind at the anemometer height in meters per second $(\mathrm{m} / \mathrm{s}), V\left(h \_h u b\right)$ is the speed of the wind at the hub height in meters per second $(\mathrm{m} / \mathrm{s})$, and $\alpha$ is the power law exponent.

Once the wind speed is adjusted accordingly, the wind turbine's output power is calculated using Eqn. (3) as

$$
P_{W T G}^{t}=\left\{\begin{array}{lr}
0 & 0 \leq v \leq v_{\text {cut-in }} \text { and } v \geq v_{\text {cut-out }} \\
\left(a * v^{3}\right)+\left(b * P_{\text {rated }}\right) & v_{\text {cut-in }} \leq v \leq v_{\text {rated }} \\
P_{\text {rated }} & v_{\text {rated }} \leq v \leq v_{\text {cut } \text { out }}
\end{array}\right.
$$

where the constants $\mathrm{a}$ and $\mathrm{b}$ in the above formula are a given by the following equations

$$
\begin{aligned}
& a=\frac{P_{\text {rated }}}{\left(v_{\text {rated }}^{3}-v_{\text {cut-in }}^{3}\right)} \\
& b=\frac{v_{\text {cut-in }}}{\left(v_{\text {rated }}^{3}-v_{\text {cut-in }}^{3}\right)}
\end{aligned}
$$

where $v_{\text {cut-in }}, v_{\text {cut-out }}$, and $v_{\text {rated }}$ are the cut in, cut out and rated speeds of the wind turbine generator respectively in $\mathrm{m} / \mathrm{s}$ and $P_{\text {rated }}$ gives the rated output power of the wind turbine generator unit in $\mathrm{kW}$.

\subsection{Storage Battery}

The storage battery is modeled using the following equation

$$
P_{b a t t}^{t}=\sum P_{p v-a c t u a l}^{t}+\sum P_{W T G-a c t u a l}^{t}-\frac{\text { Load }^{t}}{\eta_{i n v}}
$$

where $\eta_{\text {inv }}$ is the inverter efficiency, and Load ${ }^{t}$ is the load during the time unit, $\mathrm{kW}$.
The equation indicates the $\mathrm{kW}$ power flow through the battery system. The modes of operation of the battery are dependent on the battery's State of Charge (SOC). The State of Charge can be calculated using the following equation:

$$
S O C^{t+1}=S O C^{t}\left[1-\left(\frac{\sigma}{24}\right)\right]+\frac{P_{b a t t}^{t} * l(t) * \eta_{b a t t}}{E_{b a t t}}
$$

where $\eta_{\text {batt }}$ represents the efficiency of the battery, $\sigma$ gives the self discharge rate of the battery, $1(\mathrm{t})$ is the length of $\mathrm{t}^{\text {th }}$ time unit and $E_{\text {batt }}$ is the energy rating of battery storage.

In addition, the battery charging and the discharging operation is constrained by the following equations

$$
P_{\text {batt.cmax }}^{t} \leq P_{\text {batt }}^{t} \leq P_{\text {batt.dmax }}^{t}
$$

where

$P_{\text {batt.cmax }}^{t}=\left(S O C_{\text {max }}-S O C_{t}\right) * E_{\text {batt }}$ is the maximum battery charge power and

$P_{\text {batt.dmax }}^{t}=\left(S O C_{t}-S O C_{\text {min }}\right) * E_{\text {batt }}$ is the maximum battery discharge power

\subsection{Converter}

A converter helps in transferring power flow from the AC terminus to DC terminus. The efficiency of the inverter $\left(\eta_{\text {inv }}\right)$, is assumed constant and is taken as $90 \%$. The equation abiding the power flow within the converter is given by equation (9).

$$
P_{\text {inout }}^{t}=\left(P_{\text {pv-actual }}^{t}+P_{\text {WTG-actual }}^{t}+P_{\text {batt }}^{t}\right) * \eta_{\text {inv }}
$$

PV modules selected is a 36 cell polycrystalline (PV-MF $100 \mathrm{EC} 4)$ rated at $1 \mathrm{~kW}$. The WTG used is AMPAIR $3 \mathrm{~kW}, 48 \mathrm{~V}$ DC type. The cut in, cut out and the rated speed of the wind turbines is given in Table 2. The batteries are rated at $6 \mathrm{~V}, 360$ $\mathrm{Ah}(2.16 \mathrm{kWh})$. Thus 8 batteries of the mentioned rating are arranged in series to be capable of producing $17 \mathrm{kWh}$ of electricity. The DC bus voltage is fixed at $48 \mathrm{~V}$. A detailed overview of components is summarized as a Table in [15].

\section{Formulation of Optimization Function}

The objective function of the given HRES system along with other constraints is given below:

$$
\begin{gathered}
C_{\text {Total }}= \\
\operatorname{Min} \sum n_{i}\left\{R_{i} A_{i} * \frac{r_{0}\left(1+r_{0}\right)^{m}}{\left(1+r_{0}\right)^{m}-1}+\text { om } * R_{i} A_{i}\right\}+\text { Cost }_{\text {Reliability }, i}
\end{gathered}
$$

$\mathrm{i}=\mathrm{PV}, \mathrm{WTG}$, Batt, Conv

$$
\text { Cost }_{\text {Reliability }}=C_{E N S} * E E N S
$$

Subject To:

$$
\sum P_{p v-a c t u a l}^{t}+\sum P_{W T G-a c t u a l}^{t}+\sum P_{\text {batt }}^{t}+E N S^{t}=\frac{\text { Load }^{t}}{\eta_{\text {inv }}}
$$




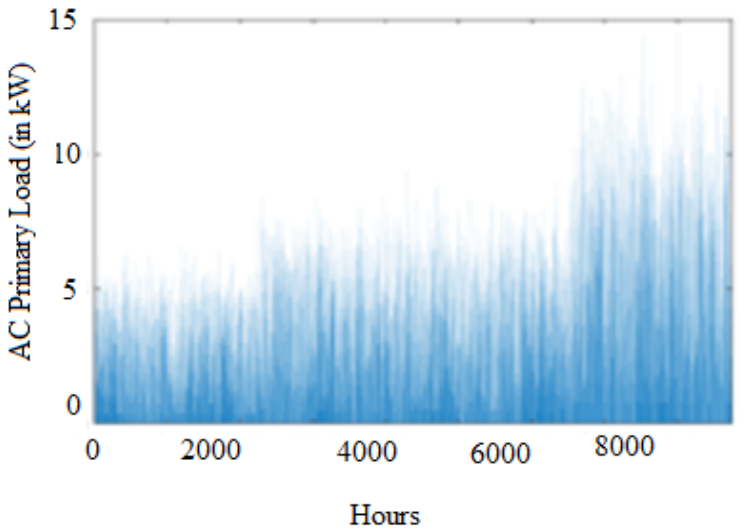

Figure 2. Hourly load profile

$$
\begin{aligned}
& \leq n_{i} \leq N \\
& S O C_{\text {min }} \leq S O C \leq S O C_{\text {max }}
\end{aligned}
$$

where $n_{i}$ represents the number of the $\mathrm{i}^{\text {th }}$ component, $R_{i}$ gives the power output capacity of the $\mathrm{i}^{\text {th }}$ component, $A_{i}$ gives the unit cost of the $\mathrm{i}^{\text {th }}$ component(in Rs/kWh), $r_{0}$ is the annual interest rate of each component in percentage, $m$ is component life time in years and om gives the running and service cost in percentage.

EENS is the expected energy not supplied(in $\mathrm{kWh} /$ year) and its cost is given by $C_{E N S} . P_{p v \text {-actual }}^{t}, P_{W T G \text {-actual }}^{t}, P_{\text {batt }}^{t}, E N S^{t}$, Load $^{t}$ are the PV power, Wind power, Battery power, energy not supplied and system load respectively at any period t. $N$ is the maximum number of the $\mathrm{i}^{\text {th }}$ component. The value for $C_{E N S}$ is fixed at Rs336/kWh.

$S O C_{\min }$ and $S O C_{\max }$ are the minimum and maximum SOC value of the storage battery respectively. Its values are fixed at $40 \%$ and $100 \%$ respectively.

\subsection{Description of Study Area}

\subsubsection{Location}

The brief description of the seven villages and its location which is considered in this paper is being summarized in a tabular format in [15].

\subsubsection{Load Profile}

On the basis of the energy requirements and the energy consumptions in the given research area, a year is divided into four seasons and its duration and peak energy requirements have been briefly discussed and converted into a tabular form in [15]. From the given data, a seasonal hourly load profile is randomly generated. The load data in Figure 2.

\subsubsection{Solar radiation}

The solar radiation data for the study area has been taken from [23]. The total solar insolation for Almora District is between $6.6 \mathrm{kWh} / \mathrm{m} 2 /$ day and $3.39 \mathrm{kWh} / \mathrm{m} 2 /$ day and the insolation for all the months throughout the year has been tabulated in [15]. Hourly solar radiations from the available data have been generated using a random reference profile. The calculated values are then plotted as shown in Fig. 3.

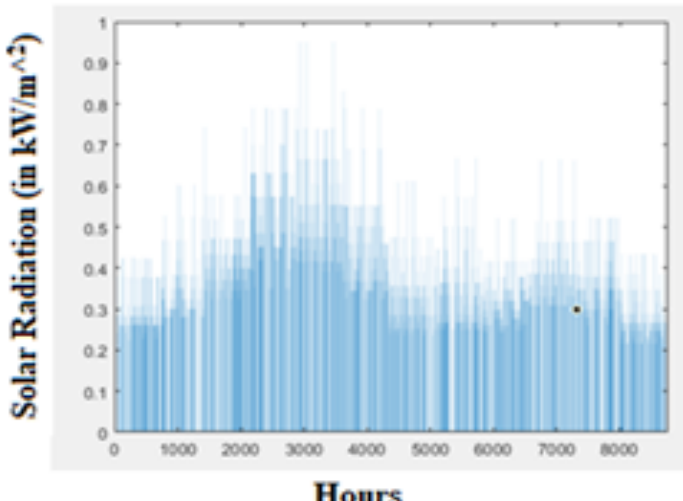

Hours

Figure 3. Hourly solar radiation profile

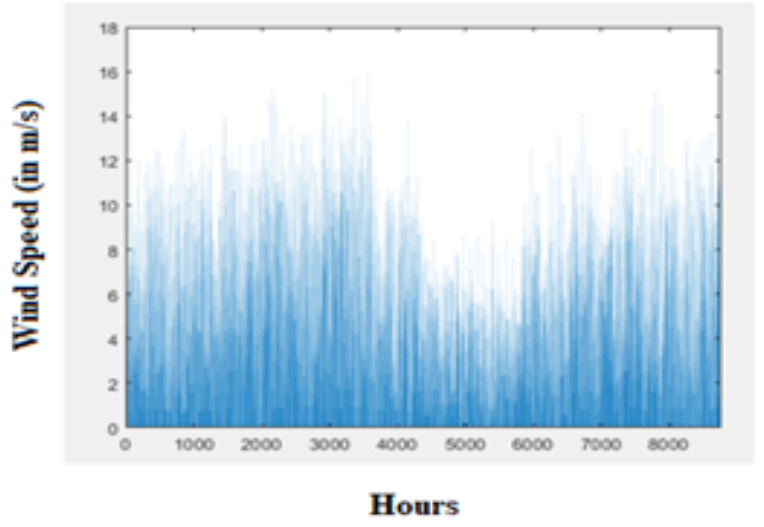

Figure 4. Hourly wind speed data

\subsubsection{Wind Potential}

The study area is said to have an average wind profile between 2 and $15 \mathrm{~m} / \mathrm{s}$. The wind speed data was measured at Almora district was obtained from [23]. In [15], the mean monthly wind speed for the given study area has been taken from. Hourly wind speeds from the available data have been synthesized using random reference values. The plot given in Figure 4 gives the hourly wind speeds for the whole year around.

\section{Implementation of Modified Differential Algorithm}

This section provides an overall view or the steps involved in the modified DE algorithm which is proposed by authors in [23]. The different steps involved in the modified DE algorithm is explained as follows:

\subsection{Initialization of parameter vectors}

$X_{i, G}$ is used to represent initial population vector which is initialized by

$$
\begin{aligned}
& x_{i, G}^{j}=x_{\min }^{j}+\operatorname{rand}\left(x_{\max }^{j}-x_{\min }^{j}\right), \\
& j=1,2, \ldots, D i=1,2, \ldots, N,
\end{aligned}
$$


where the number of decision variables is given by $D, x_{\min }^{j}$ and $x_{\max }^{j}$ are the minimum and maximum value of the decision variable $j$.

\subsection{Mutation}

The mutation strategies implemented in this algorithm are:

$$
\begin{aligned}
& M_{i, G}=X_{\text {best }, G}+F\left(X_{v_{1}, G}-X_{v_{2}, G}\right) \\
& M_{i, G}=X_{v_{1}, G}+F\left(X_{v_{2}, G}-X_{v_{3}, G}\right)
\end{aligned}
$$

where $v_{1, G}, v_{2, G}$ and $v_{3, G}$ are randomly generated exclusive integers within Nsuch that $v_{1, G} \neq v_{2, G} \neq v_{3, G} \neq i$. Here, $F$ is the mutation factor which lies between 0 and 1.2. $X_{\text {best }, G}$ is the best individual target vector corresponding to best fitness value.

\subsection{Crossover}

In DE, $u_{i, G}^{j}$ is the trial vector which is produced using the following equation:

$$
u_{i, G}^{j}= \begin{cases}v_{i, G}^{j} & \text { if } \text { rand }_{i}^{j} \leq C R \text { or } j=j_{\text {rand }} \\ x_{i, G}^{j} & \text { otherwise }\end{cases}
$$

where $C R$ is the crossover rate between 0 and 1 and $j_{\text {rand }}$ is randomly chosen integer within D.

\subsection{Selection}

The selection scheme used in this algorithm is given by

$$
X_{i, G+1}= \begin{cases}U_{i, G} & \text { if } f\left(U_{i, G}\right) \leq f\left(X_{i, G}\right) \\ X_{i, G} & \text { otherwise }\end{cases}
$$

where $f\left(U_{i, G}\right)$ and $f\left(X_{i, G}\right)$ are the fitness values of $U_{i, G}$ and $X_{i, G}$.

\subsection{Terminating condition}

Fixing the number of generations $G_{\max }$ as 100 is used as the stopping criterion in this algorithm.

Adaptation techniques for $F$ and $C R$ is used in this algorithm to eliminate the disadvantage of randomly choosing it.

\subsection{Adaption techniques for mutation rate, $F$}

The self adaptation technique used in this algorithm is given by

$$
F_{G+1}= \begin{cases}\max \left\{l_{m}, 1-\left|\frac{f_{\max }}{f_{\min }}\right|\right\} & \text { if }\left|\frac{f_{\max }}{f_{\min }}\right|<1, \\ \max \left\{l_{m}, 1-\left|\frac{f_{\min }}{f_{\max }}\right|\right\} & \text { otherwise, }\end{cases}
$$

where $l_{m}=0.4, f_{\min }$ and $f_{\max }$ are the minimum and maximum fitness values respectively.

\subsection{Adaptation technique for crossover rate, $C R$}

The self-adaptation scheme used in the DEPAS algorithm is given by:

$$
C R_{i, G+1}=\left\{\begin{array}{cl}
\operatorname{rand}_{1} & \operatorname{rand}_{2} \leq \tau_{2} \\
C_{i, G} & \text { otherwise }
\end{array}\right.
$$

In this algorithm, it is assumed that $\tau_{2}=0.1$

A flowchart to explain the process of Modified DE is given in Figure 5.

\section{Results}

The modified DE algorithm is applied to the HRES system problem in the Almora District in Uttarakhand using MATLAB. To analyze the betterment of the DE Algorithm, it is compared with PSO and GA. The various control parameters involved in the three optimization algorithms are being summarized in Table 1 .

The crossover rates in the GA are taken to be in the range between 0.6 and 1.0 whereas the mutation rates are taken to be less than 0.1. The acceleration constants in the PSO is taken in such a manner that $\mathrm{C} 2>\mathrm{C} 1$ which is generally advantageous for complex nonlinear integral problems. The crossover rates and the mutation rates are first fixed at 0.5 for both respectively. Then for every iteration, the constants are iterated and different values are obtained. The best optimized results are then obtained for the crossover rate and the mutation rate.

The convergence characteristic for the three optimization algorithms namely GA, PSO and Modified DE for the modeled HRES System is shown in Figure 6 respectively. The abscissa for the convergence plot gives the combined cost for all the components. The perpendicular axis gives the total number of iterations to reach the global minimum in each of the situations. Since the computational time for the modified DE algorithm is slightly higher than the rest of the algorithms, the number of iterations was limited to 600 , whereas the numbers of iterations were extended up to 1000 for both PSO as well as GA.

A close look at the convergence characteristics indicates that the modified DE produces faster results (obtaining the global minimum) when compared to other optimization algorithms. So although the computational time is slightly higher, the faster response helps reduce the computational complexity leading to less computer resource usage. The best optimal solutions from the three algorithms are briefed in table 2 .

\section{Conclusion}

In this paper, an attempt has been made to implement the Modified DE algorithm for solving hybrid renewable energy systems problem. The developed methodology was tested for a remote society in Uttarakhand, India and the obtained results were compared with those obtained from GA as well as with PSO. Results reveal that the Modified DE evolutionary algorithm outperforms the Genetic Algorithm as well as the Particle Swarm optimization algorithm. A hybrid system consisting of $61 \mathrm{~kW}$ PV panels, $83 \mathrm{~kW}$ WTG, a $20 \mathrm{~kW}$ converter and 10 battery strings each of $17 \mathrm{~kW}$ produces the most optimal solution for the given study area. The developed objective function substantiates the capital cost along with the running and service cost as well as the lifetime of all the components while also including the force outage rate for the Wind Turbine Generators and the SOC condition for the battery. The system can be further extended by including multi - objective function for optimization by including the transmission and line losses in the system. It also can be extended to optimize time varying data. 


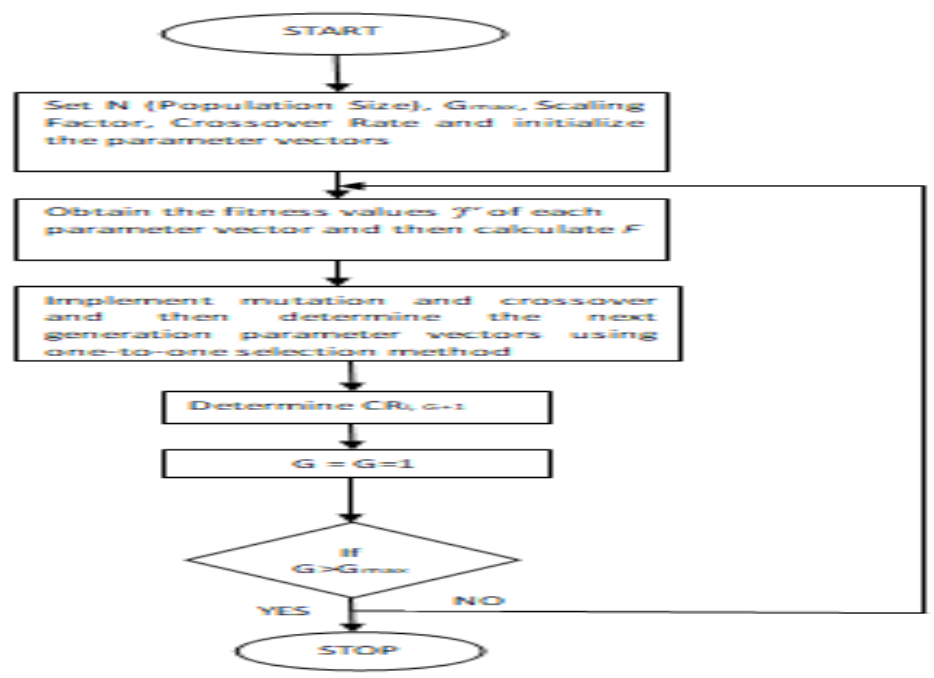

Figure 5. Flow chart of modified DE algorithm

Table 1. Control Parameters for different algorithm

\begin{tabular}{|c|c|c|c|}
\hline S/N & Optimization Technique & $\mathrm{N}$ & Control Parameters \\
\hline 1. & Genetic Algorithm & 20 & $\mathrm{Pm}=0.07, \mathrm{Pc}=0.85$ \\
\hline 2. & Particle Swarm Optimization & 30 & $\mathrm{C} 1=2, \mathrm{C} 2=3$ \\
\hline 3. & Modified Differential Evolution & 380 & $\mathrm{~F}=0.5, \mathrm{CR}=0.5$ \\
\hline
\end{tabular}

Table 2. Results obtained from Algorithms

\begin{tabular}{|l|l|l|l|l|l|}
\hline $\begin{array}{l}\text { Optimization } \\
\text { Algorithm }\end{array}$ & $\begin{array}{l}\text { No. PV Pan- } \\
\text { els }\end{array}$ & No. WTG & $\begin{array}{l}\text { No. of Battery } \\
\text { Strings }\end{array}$ & $\begin{array}{l}\text { Converter } \\
(\mathrm{kW})\end{array}$ & $\begin{array}{l}\text { Optimized Cost } \\
\text { is Rupees }\end{array}$ \\
\hline GA & 8 & 7 & 11 & 20 & 737694.48 \\
\hline PSO & 8 & 7 & 10 & 20 & 713703.416 \\
\hline $\begin{array}{l}\text { Modified } \\
\text { DE }\end{array}$ & 6 & 8 & 10 & 20 & 667960.321 \\
\hline
\end{tabular}

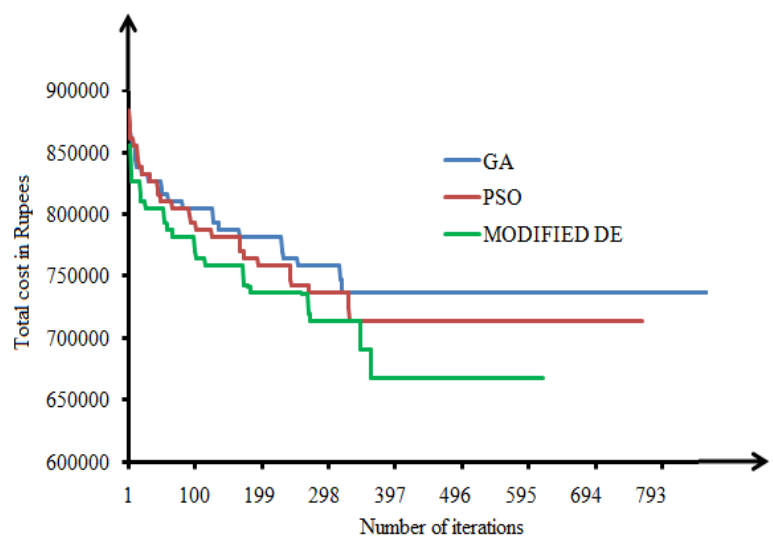

Figure 6. Convergence Characteristics of different algorithms

\section{Acknowledgements}

The authors are very grateful to anonymous referees for their contributions and suggestions.

\section{References}

[1] A, Azarpour, S. Suhaimi, G. Zahedi \& A. Bahadori, "A review on the drawbacks of renewable energy as a promising energy source of the future", Arabian Journal for Science and Engineering 38 (2013) 317.

[2] L. Rodríguez U, J. Valencia, D. Rodríguez U \& A. Martínez G, "Design, implementation and operation of a solar hybrid system in a remote area in the Colombian Guajira desert" WIT Transactions on Ecology and the Environment 195 (2015) 427.

[3] H. Soonmin, A. Lomi, E. C. Okoroigwe \& L. R. Urrego, "Investigation of solar energy - The case Study in Malaysia, Indonesia, Columbia and Nigeria", International Journal of Renewable Energy Research 9 (2019).

[4] T. Agarwal, S. Verma \& A. Gaurh, "Issues in wind energy", International Conference on Electrical, Electronics, and Optimization Techniques (ICEEOT) (2016).

[5] M. S. Pranav, S. Saravanan, V. M. Afsal, K.Karunanithi, M. Akhil \& A. Krishnan "Hybrid renewable energy resources(HRES) - A review", International Conference on Intelligent Computing, Instrumentation and Control Techniques(ICICICT).

[6] K. Joshi, S. Chandel \& A. Ashok, "Optimal economic analysis of hybrid renewable energy system", IEEE (2016).

[7] I. Elsayed, I. Nassar \& F. Mostafa, "Optimization and economic evaluation of small scale hybrid solar/wind power for remote areas in Egypt", Nineteenth International Middle East Power Systems Conference(MEPCON), Menoufia University, Egypt. 
[8] M. Amer, A. Namaane \& N.K. M'Sirdi, "Optimization of hybrid renewable energy systems(HRES) using PSO for cost reduction", The Mediterranean Green Energy Farm (2013).

[9] Y. Sawle, S. C.Gupta \& A. K. Bohre, "Optimal Sizing of standalone $\mathrm{PV} /$ Wind/Biomass hybrid energy system using GA and PSO Optimization technique", 1st International Conference on Power Engineering Computing and Control, PECCON (2017), 1876.

[10] A. Ahadi, S. Kang \& J. Lee "A novel approach for optimal combinations of wind, PV, and energy storage system in diesel-free isolated communities", Applied Energy 170 (2016) 101.

[11] H. Nabipour-Afrouzi, S. H. W. Yii, J. Ahmad \& M. Tabassum, "Comprehensive review on appropriate sizing and optimization technique of hybrid PV-Wind system" IEEE PES Asia-Pacific Power and Energy Engineering Conference(APPEEC) (2018).

[12] L. Slimani \& T. Bouktir "Application of differential evolution algorithm to optimal power flow with high wind energy penetration", Mediamira Science Publisher, 53 (2012) 59.

[13] M. S. Ismail, M. Moghavveni \& T. M. I Mahila. "Design of an optimized photovoltaic and microturbine hybrid power system for a remote small community: Case study of Palestine", Energy Conversion and Management 75 (2013) 271.

[14] M. S. Ismail, M. Moghavveni, T.M.I Mahila "Genetic algorithm based optimization on modeling and design of hybrid renewable energy systems", Energy Conversion and Management 85 (2014) 120.

[15] S. Sanajaoba \& E. Fernandez "Maiden application of cuckoo search algorithm for optimal sizing of a remote hybrid renewable energy System", Renewable Energy, 96 (2016) 1.

[16] H. Hardiansyah "Modified differential evolution algorithm for economic load dispatch problem with valve-point effects", International Journal of Advanced Research in Electrical, Electronics and Instrumentation Engineering 3 (2014) 2275.

[17] Deepti Gupta and Rupali Parmar, "Optimization of economic load dispatch thermal power plant using differential evolution technique", International Journal of Engineering Trends and Technology (IJETT) 22 (2015) 2231.

[18] C. Kumar \& T. Alwarsamy "Solution of economic dispatch problem using differential evolution algorithm", International Journal of Soft Computing and Engineering 1 (2012) 236.

[19] N. C. Cuong "Differential evolution algorithm for optimal power flow and economic load dispatch with valve point effects", The International Journal Of Engineering and Science 3 (2014) 15.

[20] V. Kachitvichyanukul, "Comparison of three evolutionary algorithms: GA, PSO, and DE”, Industrial Engineering \& Management Systems 11 (2012) 215.

[21] G. R. Venkatakrishnan, J. Mahadevan \& R. Rengaraj, "Differential evolution with parameter adaptation strategy to economic dispatch incorporating wind", Intelligent and Efficient Electrical Systems (2018) 153.

[22] Venkatakrishnan, G. R, Rengaraj, R, "Differential evolution with parameter adaptation strategy for an optimal dispatch of residential distributed energy sources ", Journal of Computational and Theoretical Nanoscience, 14 (2017) 5997.

[23] Vivekananda Parvatiya Krishi Anusandhan Sansthan, Indian Council of Agricultural Research (ICAR) Laboratory, Almora, Uttarakhand, India (2002). 